\title{
Gravity flow research at the Kiruna sublevel caving mine during the last decade and an outlook into the future
}

\author{
A Nordqvist LKAB Kiruna, Sweden \\ M Wimmer LKAB Kiruna, Sweden \\ M Grynienko LKAB Kiruna, Sweden
}

\begin{abstract}
$\angle K A B$ operates two underground iron ore mines located in the northern part of Sweden, both using sublevel caving as mining method. Knowledge of the mechanisms of gravity flow is important since it affects both ore recovery and waste dilution. This paper summarizes results from research conducted during a decade at the Kiruna mine with focus on gravity flow. Two large scale field tests have been carried out, both adopting a holistic approach, not only the gravity flow being monitored but also possible factors influencing the flow. The results from these tests clearly shows that the gravity flow in large scale SLC in Kiruna is often of disturbed character. Shallow draw has been documented both in marker trials but also in many hang-up situations. Shallow draw is common especially in the northern part of the orebody and appears to be rock mass dependent. However shallow draw does not necessarily mean poor extraction ratio, in fact there are many examples on the opposite. The results from the two large scale field trials confirm also a relation between fragmentation and the width of the draw, 10-13 $\mathrm{m}$ for fine fragmentation (test 1) and 11-16 $\mathrm{m}$ for coarser fragmentation (test 2). A stepped ring design has been tested addressing shallow draw issues, the results appear promising. Several other tests are now ongoing to optimize the current SLC parameters based upon the findings from this research. Recently, the industrial development project "SUM" (Sustainable Underground Mining) has been launched. Part of that project are tests on extreme sublevel heights $(40$ and $50 \mathrm{~m})$ in a dedicated test mine. Gravity flow will be monitored in all these upcoming trials, but a customized approach will be adopted. A very interesting and challenging future is to come.
\end{abstract}

\section{Introduction}

Sublevel caving (SLC), see Figure 1, is a mass mining method based upon the utilization of gravity flow of blasted ore and caved waste rock (Kvapil 1998). It relies on the principle that ore is fragmented by blasting while the overlying host rock fractures and caves under the action of mine induced stresses and gravity. Thereby the caved waste originating from the overlying rock mass fills the temporary void created by ore extraction. SLC is used in LKAB's Kiruna mine since mining transferred underground in the early 1960 s.

To remain profitable from ever increasing depths in an extremely competitive iron ore market the scale has changed substantially since then in order to keep specific drift development low, see Figure 2 . This scale-up goes hand in hand with the technological progress in drilling and charging techniques.

The actual SLC ring design is essentially affected by gravity flow aspects. The Kiruna mine nowadays applies a silo-shaped design (shoulder hole drill angle $73^{\circ}$ ) which favors primary recovery. It reflects well the marker trials made at the late 1990s in which flow was found to occur within a relatively narrow zone (Larsson 1998; Quinteiro et al. 2001). Curiously enough, silo-shaped ring designs were already tested in the early years but could not prevail because of the accuracy in drift development and drilling being rather poor (Kullman \& Hermansson 1971). However, an increased primary recovery does not necessarily show up in the run-of-mine figures. Persisting to use the fan-shaped design, the shorter and flatter side holes still fulfill the function of pre-breaking. Losses are again minimized with the staggered drift pattern. That seems to be the case with LKAB's Malmberget mine which still uses the fan-shaped design (shoulder hole drill angle $60^{\circ}$ ) with a comparable overall result. 


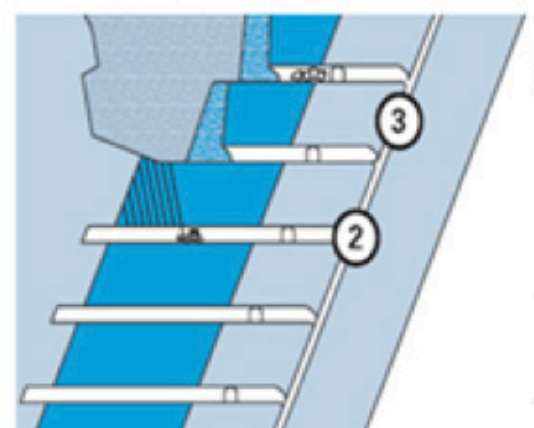

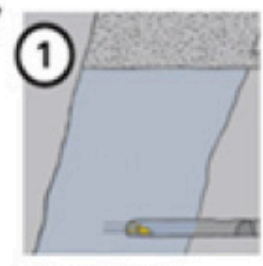

Development

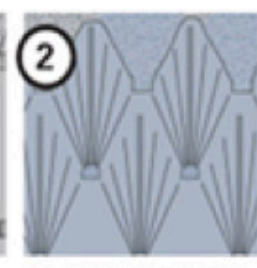

Production drilling

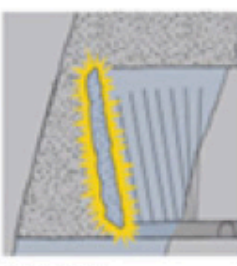

Blasting

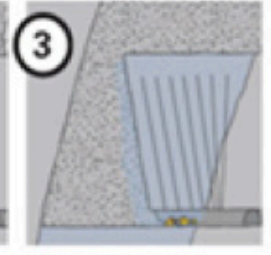

Loading caved material

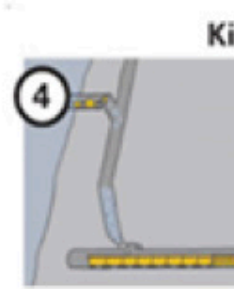

Dumping and loading to train at main level.

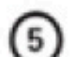

Kiruna

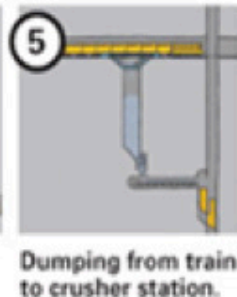

to crusher station.

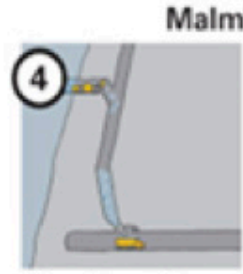

Dumping and main level.
2020/21 (test mine)

Future designs ??

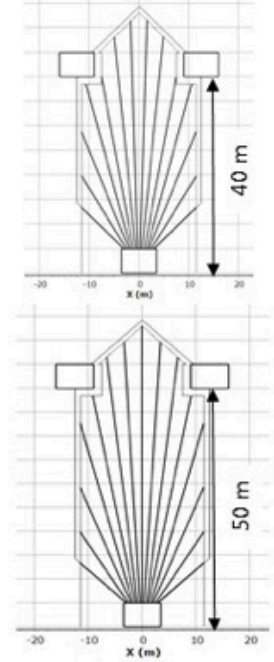

2008

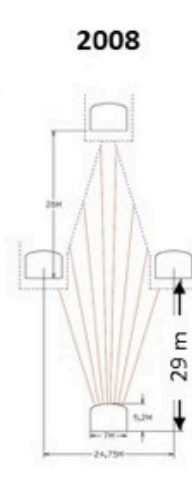

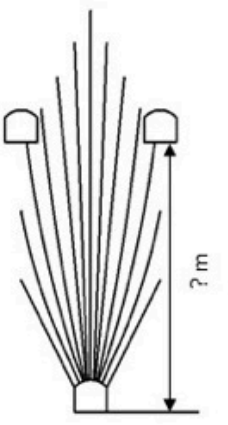

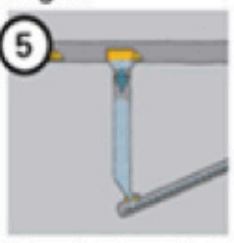

Dumping from trucks to erusher station.

Figure 1 Sublevel caving in LKAB's iron ore mines

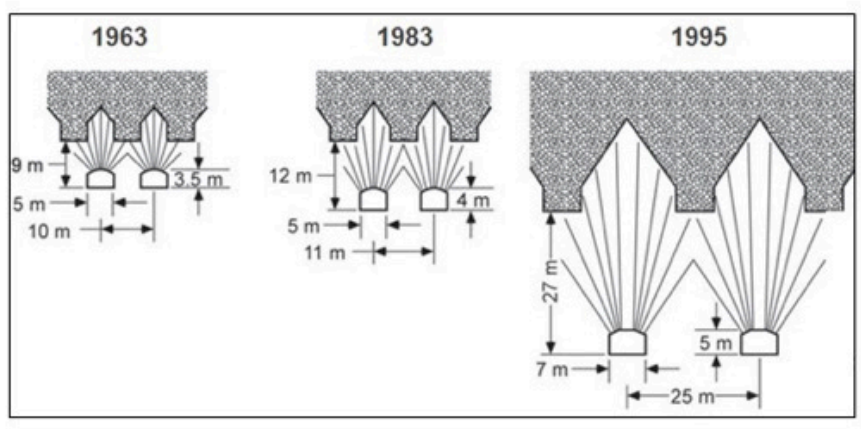

Hustrulid \& Kvapil 2008

Figure 2 Evolution of scale and design for SLC rings, Kiruna mine (left part from Hustrulid \& Kvapil 2008)

Specific drift development was dramatically reduced in 1990s, but since then basically unchanged. The drift spacing cannot be widened drastically without impacting the long-term recovery. Still, for practical reasons, it cannot either be closer to promote interactive draw in adjacent drifts. The height of the siloshaped rings is considered to be fairly close to its workable limit. A further increase implies increased problems with drilling and charging of long holes, and possible higher dilution over a longer draw duration. Hence, the current demand to stepwise up-scale for a $50 \mathrm{~m}$ sublevel height can only be met by returning to a fan-shaped design, see Figure 2 . This trial is currently implemented in a test mine (Quinteiro 2020). In parallel, LKAB's subsidiary Wassara works on the development of a coil drilling system for mining applications (Forslund 2018). Its principles have been used for decades in the oil industry. It basically consists of a continuous drill tube winded on a large diameter reel. The system also includes steering capabilities and a water-driven DTH hammer incorporating also rotation. This enables drilling of curved holes in the lower part of a ring and parallel holes in the upper part. It is expected to lead to a paradigm shift with unrivalled precision and seamless drilling. 
LKAB's competitiveness highly depended throughout the years on the use of cutting-edge mining technology but also the R\&D work related specifically to better understand the functionality of large scale SLC. At the heart of the SLC process lie the core elements blast function, fragmentation, and gravity flow (Wimmer 2012). For the ore recovery to be as high as possible and for the waste rock dilution to be as low as possible all three elements must work as planned. They are affected by several given factors and controllable factors. The effect of rock mass characteristics and a semi-confined blasting situation are largely unknown. The controllable factors are related to mine planning (SLC and ring design), charge and initiation pattern, performance of drill and blast work, and draw control. All three elements were intensively investigated in different projects in the last decade. Even though most of the research has a reference to the Kiruna mine, generally valid conclusions can be drawn on confined blasting and its impact upon material flow characteristics. The present paper gives a synopsis of the research together with an outlook of future actions to implement the learnings in production.

\section{Present-day tools in SLC research}

\subsection{Marker tests}

Gravity flow has been studied throughout the years by so-called markers installed in extra boreholes within the burden (Kullman \& Hermansson 1971; Larsson 1998). They should sustain the blast, follow the gravity flow and end up at the muck pile where they can be detected. It was common practice to use simple markers e.g. pieces of steel cables with unique identity. However, the required manual detection was both tedious and imperfect. In recent years, markers based on long-lasting, shock-proof RFID technology (Whiteman 2010) became available which enable a much more reliable detection. Due to the high attenuation of radio waves in magnetite the marker id cannot always be reliably detected from the filled LHD bucket, but markers are successfully detected at the ore pass while dumping.

In the current tests an intense coverage of the blasted SLC ring with regards to both depth, width and height is sought which leads to an all-time high measurement resolution for gravity flow. For this purpose, 3 marker rings with up to 18 additional boreholes are drilled within a $3 \mathrm{~m}$ burden, containing about 250-300 markers. A prerequisite for an accurate evaluation is the detailed survey of all boreholes (Wimmer et al. 2014). The holistic approach of recent marker tests requires measurement of several factors influencing the gravity flow:

- Blast performance is verified by high-speed filming, near-field vibration monitoring and VoD measurements. The charging procedure is documented.

- Fragmentation is evaluated from images with different techniques (Wimmer et al. 2015; Stauder 2018) Mucking at the draw point is closely monitored with regards to the position of the LHD bucket during filling, the corresponding inflow and possible flow disturbances, weight and volume of the filled bucket.

- Flow disturbances are also monitored in open caverns using laser scanning and taking photos from a very long boom.

The preparation and realization of suchlike tests is a long-term project.

\subsection{D surveys}

Both the actual blasted geometry and the breakage itself are hidden in the controlled SLC mining operation, which makes it very difficult to observe the actual blasting result. However, under certain conditions observations are possible in an open cavern, e.g. in the opening phase, remnant pillar situations or hang-ups.

This idea was originally implemented in a test area in the LKAB Malmberget mine with blasts into an open cavern, which allowed taking photographs in steps from the bottom to the top of 3 ring faces (Rustan 1993). The subsequent interpretation of 2D images stitched together led to revised design rules 
and to a recommendation for an increased minimum distance between charged boreholes to obtain undisturbed detonations.

This idea was reapplied and given the tremendous development in imaging technology since then, several different systems were used in the past (Wimmer et al. 2012a; Nordqvist \& Wimmer 2014). They did deliver accurate, colored 3D data at a low hardware cost, which is relevant given the risk of sudden rock fall or even collapse of the surveyed cavern. To enhance safety against rock fall, an additional pile of material is loaded close to the brow in-front of the carrier. The actual measurement system is mounted at the end of a very long boom (about $20 \mathrm{~m}$ ).

A reasonable large data set with totally 30 surveyed SLC ring blast inside openings was evaluated (Wimmer et al. 2012a). This made it possible to study, i) broken geometry and height, ii) over- and underbreak and their effects on subsequently blasted rings, iii) interaction effects between adjacent holes/rings, iv) mapping of geological structures and their influence on the blast result, and v) drilling accuracy based on identified boreholes. In an attempt to categorize breakage problems also a considerable proportion ( $10 \%$ of the incompletely broken holes) was found to be caused by undetonated charges. There are many possible reasons for non-detonating boreholes. Trying to reduce/eliminate these problems has been a focus through many years (Nordqvist 2013).

In the past focus was on a specific hang-up type, see Figure 3. The actual hang-up evolves from an obstruction in the upper part of the extracted SLC ring caused by either incomplete breakage or clogging of the flow zone during the extraction. Such 'frozen' hang-up situations, in which a temporarily stable arch is built up during further extraction, might be viewed as a snapshot to investigate the blast result and its effect on gravity flow. Depending on the actual stability conditions, several of the previous SLC rings might be uncovered. With continued extraction, the cavity enlarges and finally become unstable, collapses and both previously 'frozen' ore and waste enter the draw point periodically.

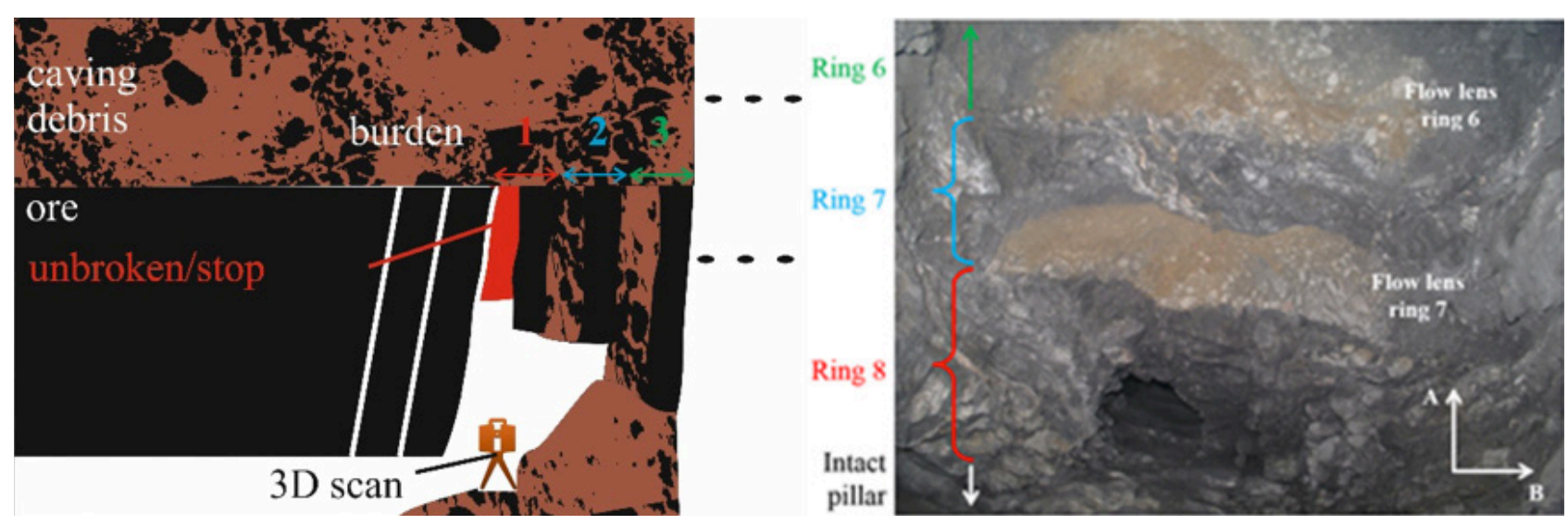

Figure 3 Principle sketch of surveyed hang-ups (left), example of hang-up observation (looking up) with gravity flow lenses from a shallow draw situation (right)

To date, about 15 surveys are existent. Especially interesting are the surveys in conjunction with the extraction of marker rings which allowed relevant findings on breakage and flow mechanisms (Wimmer \& Nordqvist 2018).

\subsection{Blasting experiments}

Small-scale flow models have provided important input for the design of block and sublevel cave mines from the beginning despite numerous limitations (Wimmer 2010). It was recognized that small-scale flow modeling also needs to incorporate blasting due to the importance of material properties on flow behavior (Rustan 2000). As a result, SLC designs were laboriously reproduced in scale (Rustan 2012; Zhang 2004). In recent years, the focus was consciously on simple test geometries, which should allow 
parametric analysis for blasting against confinement (Johansson 2011). Petropoulos (2017) went onestep further and studied the behavior of the confining material with a specially developed impact test machine, which should mimic blasting conditions.

Parallel to lab work a series of drift wall blasting tests were carried out in the last decade (Olsson et al. 2009; Wimmer et al. 2012b; Petropoulos 2017). The basic idea has been to instrument the burden with various sensors to study the effect of confinement on burden movement dynamics and breakage in full-scale. Studies of burden movement have been carried out in the past with various systems ranging from very simple to advanced ones but with installation in-front of the blast. By contrast, the recent tests required the measurement of burden movement from the reverse side. All measuring equipment must therefore be installed inside a borehole or alternatively at the borehole collar. The drift wall blasting tests were primarily for the development of suitable measurement methods, but important findings in still idealized situations were also obtained.

The methods developed could be finally employed in full-scale (Petropoulos 2020). This allowed an insight into the processes from the time of first burden movement until final extraction at the respective level.

\section{$3 \quad$ Trials and results}

\subsection{Holistic approach (marker tests)}

The first two marker trials were carried out using a holistic approach. Not only the gravity flow was monitored but also possible factors influencing the flow (see section 2).

\subsubsection{Marker trial 1}

Marker trial 1 was carried out in the northern part (block 12) of the mine. The main findings are as follows (Nordqvist \& Wimmer 2016; Wimmer \& Nordqvist 2018):

- The gravity flow appears often to be of a disturbed character, shallow draw occurred in 7 of 10 rings. Five of these developed to standard draw rather late during extraction (70-125 \%).

- The draw reaches the upper cave early (5-25\% extracted) in shallow draw situations and much later in standard draw situations (about $50 \%$ ).

- The draw is narrow (10-13 $\mathrm{m})$ in most cases.

- Waste originates from above in most cases, more significant portions often after 20-45\% extracted. Waste from in-front (and above) of the ring may limit the extraction and cause high dilution, especially in standard draw situations when draw might deepen larger than the actual burden.

- Shallow draw does not necessarily mean poor overall extraction. In fact, it can be a preventive measure for uncontrollable waste rock inflow from in-front.

\subsubsection{Marker trial 2}

The second marker trial was carried out in the middle part (block 26) of the orebody where somewhat coarser fragmentation is expected compared to trial 1. The overall layout was similar with the first trial (Nordqvist \& Wimmer 2014). The trial was carried out in two neighbouring cross-cuts, drift 270 and 272 at level $1051 \mathrm{~m}$. In total 7 rings in each drift were monitored. The first ring (id 0) was located in-front of the test area, the actual test area (ring id 1-5) contained markers in the burden and the last ring (id 6) was located behind the test area. One extra hole was drilled at each side in drift 272 to widen the opening at the draw point, see Figure 4. 


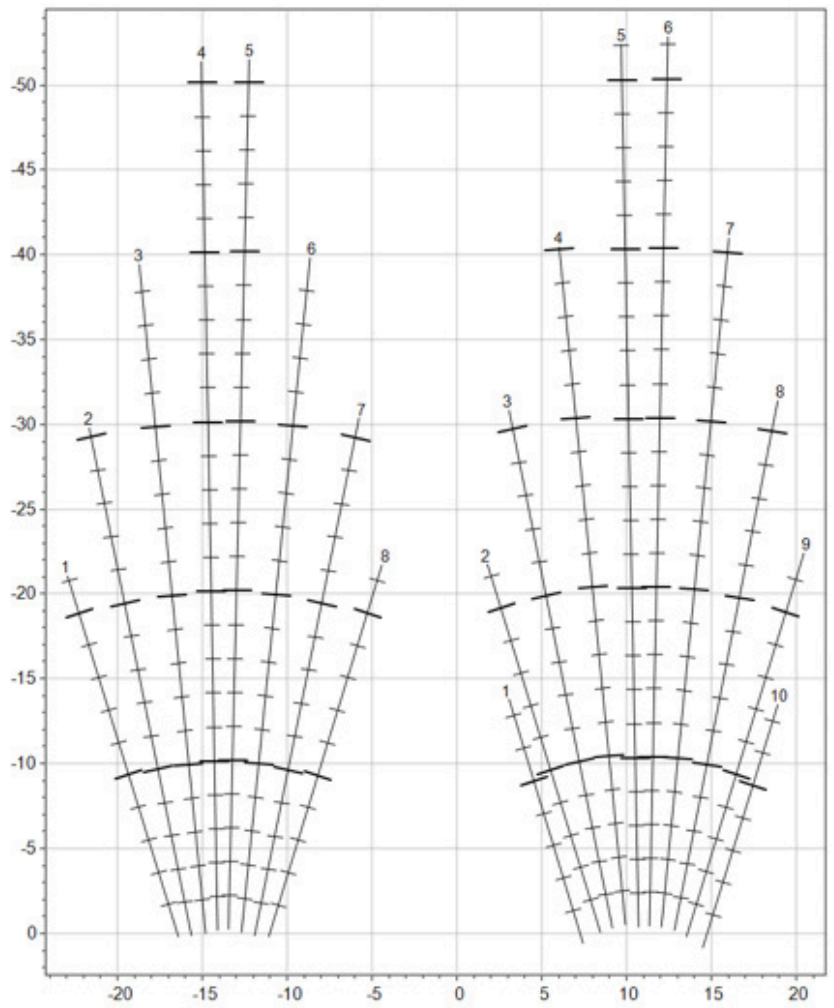

Figure 4 Front view of a ring in drift 270 (left) and 272 (right). Note the extra side holes, 1 and 10, in drift 272

\subsubsection{Marker recovery}

Table 1 summarizes the number of installed and detected markers, the overall marker recovery was 58\% (53\% in marker trial 1). Besides installation of markers in the burden, six markers were installed in crosscuts (in the ditch) at the level above $(1,022 \mathrm{~m})$.

Table 1 Installed and detected markers

\begin{tabular}{|c|c|c|c|}
\hline \multirow{2}{*}{ Marker location } & \multicolumn{2}{|c|}{ Number of markers } & \multirow{2}{*}{$\begin{array}{c}\text { Marker } \\
\text { recovery (\%) }\end{array}$} \\
\cline { 2 - 3 } & Installed & Detected & 60.7 \\
\hline Marker rings in drift 270 & 1,268 & 770 & 55.5 \\
\hline Marker rings in drift 272 & 1,246 & 692 & 0 \\
\hline In cross-cuts at level 1,022 m & 6 & 0 & 58.0 \\
\hline In total & 2,520 & 1,462 & \\
\hline
\end{tabular}

None of the markers at level 1,022 were detected at level 1,051 m, which is not surprising because of the large lateral distance to the draw point. Detection of markers in buckets filled with magnetite is not faultless (Nordqvist \& Wimmer 2016) and requires also a detection at the ore pass. Markers were detected in cross-cuts in marker trial 1 but at a fairly large distance $(20-40 \mathrm{~m})$ from the draw point. The marker recovery was only $38.6 \%$ in these locations but $51.4 \%$ at the ore passes. In the second marker trial this issue was addressed by installing the antenna much closer $(10-20 \mathrm{~m})$ so that also the markers appearing at the draw point are captured when entering the draw point. 
Table 2 Detected markers at different Reader locations

\begin{tabular}{|c|c|c|c|}
\hline Reader location & $\begin{array}{c}\text { Number of } \\
\text { detected markers }\end{array}$ & $\begin{array}{c}\text { Marker } \\
\text { recovery (\%) }\end{array}$ & Notes \\
\hline Ore pass & 1,387 & 55.0 & Dumping the bucket \\
\hline Drift 270 & 764 & 30.3 & $\begin{array}{c}\text { Reader antenna about 10-20 m from the } \\
\text { draw point }\end{array}$ \\
\hline Drift 272 & 615 & 24.4 & $\begin{array}{c}\text { Reader antenna about 10-20 } \mathrm{m} \text { from the } \\
\text { draw point }\end{array}$ \\
\hline Drift 270-272 & 1,379 & 54.7 & \\
\hline In total & 1,462 & 58.0 & \\
\hline
\end{tabular}

With this approach, marker detection close to the draw point appears to be as efficient as at the ore passes. The obvious practical drawback with this location is the need of uninstalling the antenna before blasting and reinstalling it after blasting.

There are some few markers detected at the draw point but not at the ore pass and vice versa. Combining all locations gives the final marker recovery.

\subsubsection{Draw zone width}

The extra side holes (see Figure 4) resulted in an increased average draw point opening width by $0.86 \mathrm{~m}$, see Figure 5 . The final width of the draw has been estimated using detected markers in their surveyed locations, see Figure 5. There is an insignificant difference on average between the drifts, but the widest two draws were measured in drift 272. The number of rings in this test is far too small to draw any definite conclusions.
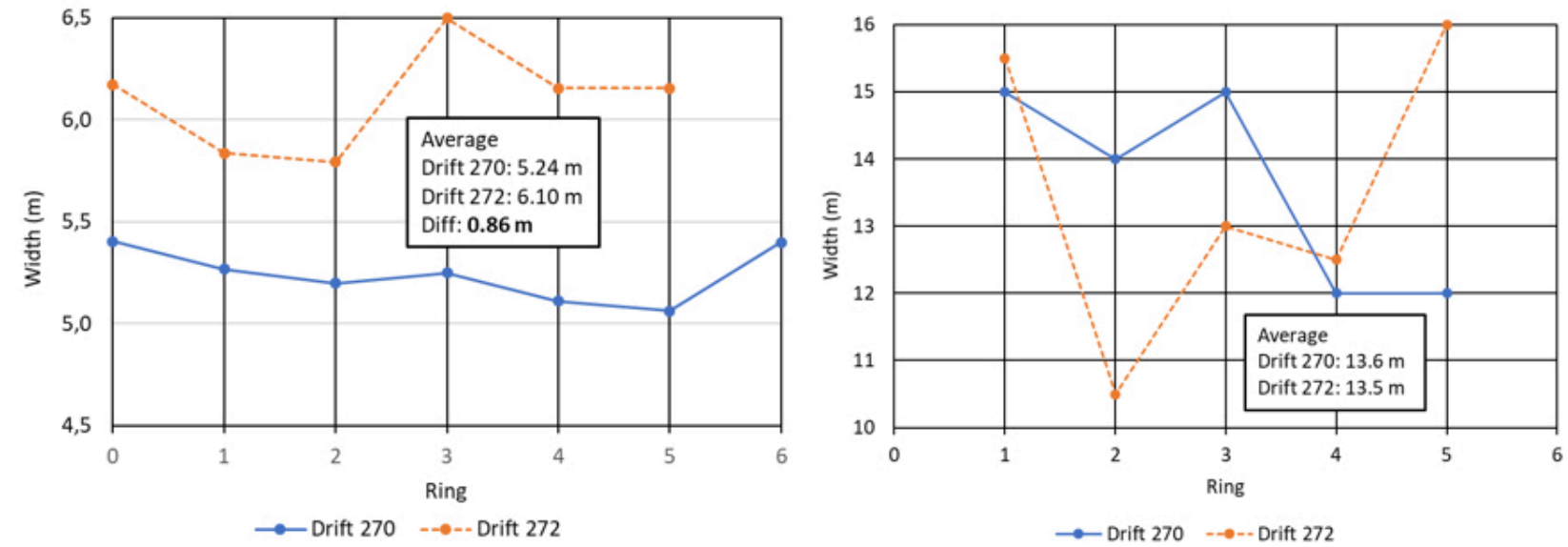

Figure 5 Opening width at the draw point (left) and final width of the draw (right)

The average width (13.6 m) should be compared with trial $1(10.9 \mathrm{~m})$. It is believed that the difference is related to fragmentation. Coarser fragmentation gives a wider draw but issues during loading and further material handling may arise.

\subsubsection{Loading and extraction}

Loading and extraction data are summarized for the rings in Table 3. The overall results in terms of extraction and dilution are very good. The waste dilution is $25-28 \%$ which is normal, the ore recovery is in fact more than $100 \%$ in both drifts. The reasons are three rings with very high extraction (> about 
$300 \%)$. There are also rings with poor performance which can be related to severe charging problems due to shearing of boreholes in the upper part of many rings. In summary these figures reflect the behaviour of large scale sublevel caving in Kiruna. Large variations between rings are common, but the overall performance is good. It is a well-known fact that ore remnants can be recovered at levels below but there is of course no $100 \%$ guarantee for that.

Table 3 Loading and extraction

\begin{tabular}{|c|c|c|c|c|c|c|c|c|c|}
\hline \multirow[t]{2}{*}{ Drift } & \multirow[t]{2}{*}{ Ring } & \multicolumn{3}{|c|}{ Total } & \multicolumn{3}{|c|}{ Ore } & \multicolumn{2}{|c|}{ Waste } \\
\hline & & $\begin{array}{l}\text { In-situ } \\
\text { (tonnes) }\end{array}$ & $\begin{array}{l}\text { Loaded } \\
\text { (tonnes) }\end{array}$ & $\begin{array}{l}\text { Extr. } \\
(\%)\end{array}$ & $\begin{array}{l}\text { In-situ } \\
\text { (tonnes) }\end{array}$ & $\begin{array}{l}\text { Loaded } \\
\text { (tonnes) }\end{array}$ & $\begin{array}{c}\text { Recov. } \\
(\%)\end{array}$ & $\begin{array}{l}\text { In-situ } \\
\text { (tonnes) }\end{array}$ & $\begin{array}{c}\text { Dilution } \\
(\%)\end{array}$ \\
\hline \multirow[t]{8}{*}{270} & 0 & 8,562 & 8,678 & 101 & 8,562 & 7,102 & 83 & 0 & 18 \\
\hline & 1 & 8,419 & 8,709 & 103 & 8,419 & 6,600 & 78 & 0 & 24 \\
\hline & 2 & 8,242 & 8,266 & 100 & 8,242 & 6,066 & 74 & 0 & 27 \\
\hline & 3 & 6,657 & 30,861 & 464 & 6,573 & 24,351 & 371 & 85 & 21 \\
\hline & 4 & 7,794 & 5,448 & 70 & 7,689 & 3,652 & 48 & 105 & 33 \\
\hline & 5 & 8,118 & 6,785 & 84 & 8,053 & 3,632 & 45 & 64 & 46 \\
\hline & 6 & 7,322 & 5,646 & 77 & 7,322 & 4,232 & 58 & 0 & 45 \\
\hline & $0-6$ & 55,114 & 74,393 & 135 & 54,860 & 55,635 & 101 & 254 & 25 \\
\hline \multirow[t]{8}{*}{272} & 0 & 9,188 & 8,983 & 98 & 9,188 & 7,231 & 79 & 0 & 20 \\
\hline & 1 & 8,795 & 29,908 & 340 & 8,795 & 27,290 & 310 & 0 & 9 \\
\hline & 2 & 7,299 & 6,744 & 92 & 7,299 & 4,949 & 68 & 0 & 27 \\
\hline & 3 & 7,861 & 8,417 & 107 & 7,861 & 5,196 & 66 & 0 & 38 \\
\hline & 4 & 8,205 & 8,446 & 103 & 8,205 & 5,809 & 71 & 0 & 31 \\
\hline & 5 & 7,245 & 9,351 & 129 & 7,207 & 6,767 & 94 & 38 & 28 \\
\hline & 6 & 9,376 & 27,967 & 298 & 9,328 & 14,887 & 160 & 48 & 47 \\
\hline & $0-6$ & 57,968 & 99,816 & 172 & 57,883 & 72,129 & 125 & 86 & 28 \\
\hline Both & $0-6$ & 113,082 & 174,209 & 154 & 112,742 & 127,764 & 113 & 340 & 27 \\
\hline
\end{tabular}

Shallow draw appears also in this trial (8 of 10 rings), detected markers are often located close to the ring plane (in-front and behind) in the beginning of extraction. Often, they originate from high up in the ring which indicates the presence of a gap directly after blasting or developing early during extraction. However, shallow draw develops towards deeper draw much earlier during extraction (5-25\%) than within trial 1 (70-125\%).

\subsection{Stepped SLC ring design}

In order to optimize the SLC production in terms of ore recovery and dilution an altered ring design was tested. It implies the same "stiff" blasting situation leading to the necessary compaction of the cave masses, but deepens shallow draw by changes in ring design, see Figure 6. 

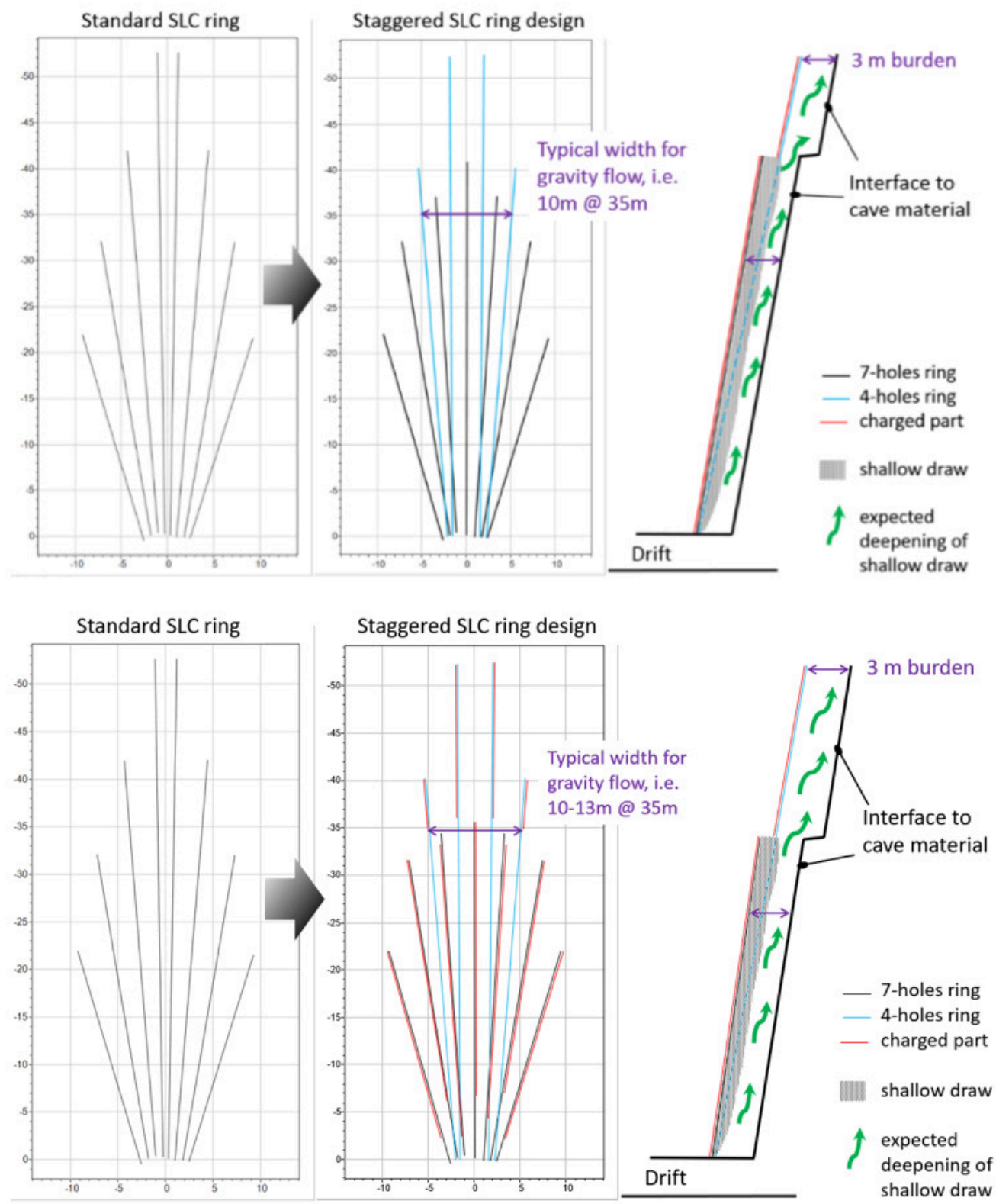

\section{Figure 6 Stepped SLC ring design}

The stepped SLC ring design induces an "artificial hang-up" corresponding to a temporary hang-up, which might preferably develop and allow a shallow draw to deepen. The burden between rings is not changed and remains constant, $3 \mathrm{~m}$. The expected result of the test is that very limited dilution occurs up to about $50-70 \%$ of extraction, i.e. up to the maximum expected primary recovery. A retained/increased Fe recovery at a lower extraction rate should outweigh the extra effort for drilling and charging.

A field test with a stepped ring design was carried out in block 9 at level $935 \mathrm{~m}$ in drift 94 . The design was applied on already drilled 8-holes standard rings. The upper part of the existing holes was instrumented by markers and four extra holes were additionally drilled in-front. Seven consecutive rings starting from ring number 37 were prepared for the trials. Five rings ("test ring 1-5") with successful execution of design and installation of RFID markers within the burden were qualified for assessment. In total, 264 markers were installed, and 137 markers (52\%) were recovered and detected at relevant ore-passes.

Operational data collected from markers installed in relevant parts of the burden confirmed the success of the stepped ring design in terms of propagation of preferential flow of blasted material. It caused the very same stiff blasting as expected for this rock mass which led to a well-defined interface against cave masses preventing the lateral inflow of waste material. Additionally, the induced "hang-up" hindered shallow draw from development up to the cave and facilitated its deepening and reaching upper parts 
of the ring plane. However, markers in the ring's apex were scarcely detected, see Figure 7 . This could be explained by either poor breakage and immobilization in the apex or simply by markers remaining at the bottom of the draw point.

The loading data derived from LKAB's LHD bucket weighing system "WOLIS" (Wireless Online Loader Information System) was accordingly analyzed. In Figure 8 the Fe content during extraction is shown for the respective rings.
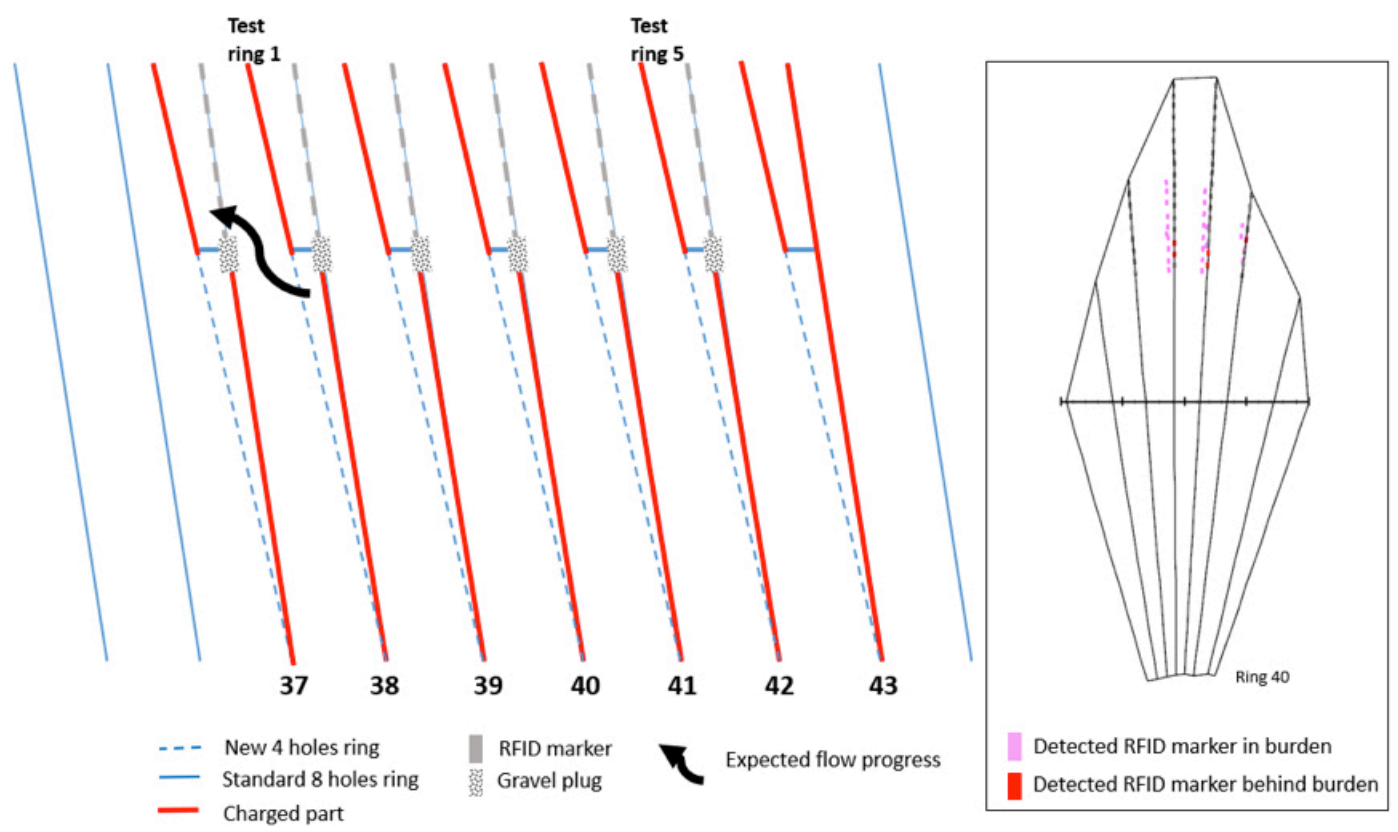

Figure 7 Side view of stepped SLC ring design (left) and example of markers detection to the right (front view of ring 40)

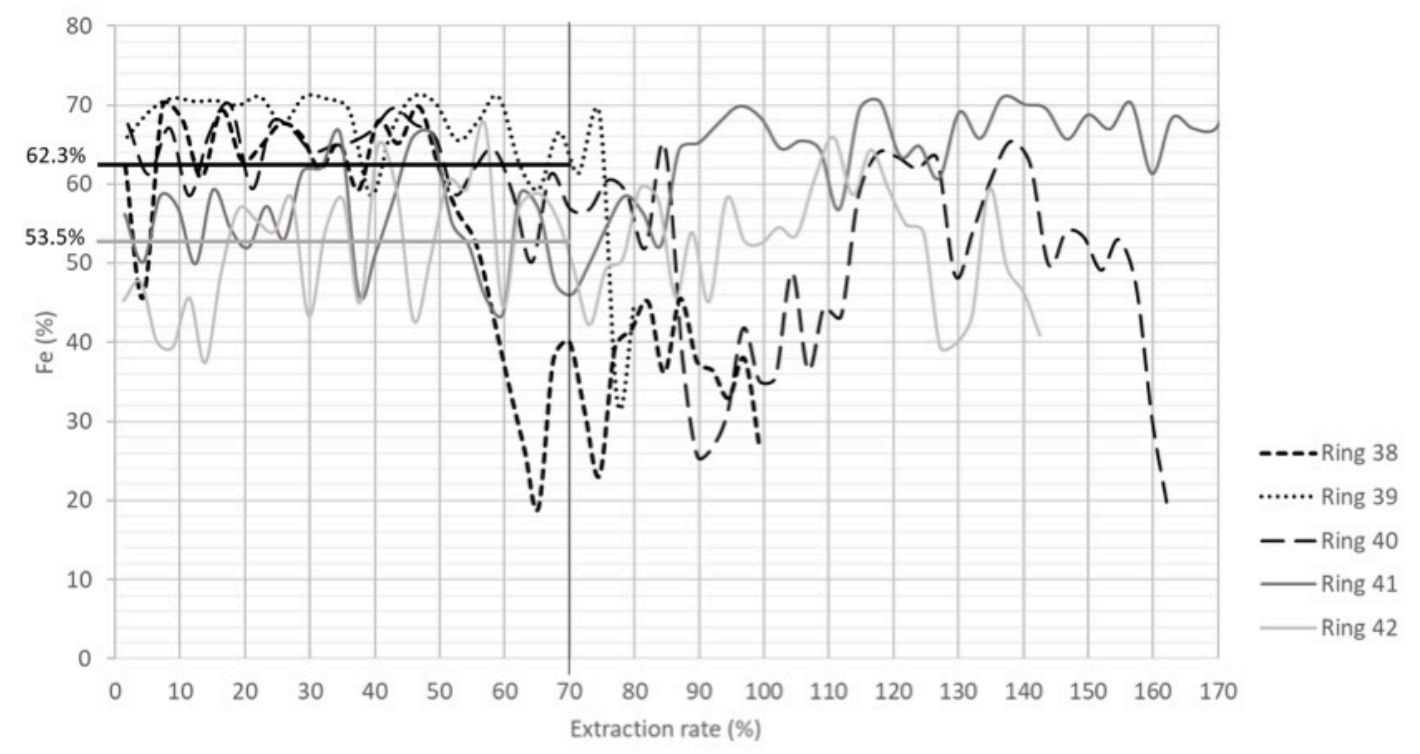

Figure 8 Fe content versus extraction rate for the test rings

Overall performance of ring extraction rate and Fe content was positively assessed; however, some discrepancies have occurred. The extraction rates ranged from $82 \%$ to $164 \%$ with ore recoveries of $74 \%$ to $132 \%$. One of the rings (ring 41 ) obtained extreme performance with $745 \%$ of extraction and $651 \%$ of recovery (data in Figure 8 cut at 170\%), likely caused by cumulative inflow of remnant ore from above. Such cases do exist in standard production but were considered as not representative for this test.

The Fe content for rings 38, 39, and 40 remained high during initial phase of loading. More considerable dilution occurred after $65 \%, 78 \%$, and $88 \%$ of extraction respectively. Each of the three consecutive 
rings reached a high average Fe content up to $70 \%$ of extraction (previous acceptance criteria). The obtained Fe content was $56 \%, 68 \%$, and $63 \%$ respectively with an average of $62.3 \%$.

The rings 41 and 42 present more fluctuating Fe content initially. Until 70\% extraction they obtained a Fe content of $55 \%$ and $52 \%$ respectively with an average of $53.5 \%$.

The objectives of the stepped ring design were partially obtained, including drill and blast design, material flow, and delayed entry of dilution. Three out of five rings were assessed as entirely successful in terms of high Fe content and delayed dilution up to $70 \%$ of extraction. The ratio of ore recovery to extraction rate was satisfactory for all tested rings with minimum of 0.74 and maximum of 0.94 despite no significant influence from LHD operator to actively control the end of loading was requested.

Summarizing the performance of all tested rings and comparing them to the results from five consecutively standard blasted rings in several neighboring drifts, the obtained Fe content was higher by $1-2 \%$. In addition, the extraction rate for the suggested design could have been reduced. This must be further evaluated in terms of economics whether costs of extra drilled/charged meters can be compensated by the gain. Nevertheless, it is also important to point out that only 5 rings were tested and that the obtained results may not be representative for other sections across the orebody, where geological and geotechnical conditions may differ, and therefore influence the applicability of this design.

\section{$4 \quad$ Up-coming trials}

\subsection{Customized marker installation}

A holistic approach was adopted in marker trials 1-2 using current available technologies. Many interesting results were revealed and an increased understanding on the functionality of large scale SLC was obtained. The results from marker trial 1-2 also raised some important questions, especially on the width and the depth of the draw. The stepped pattern layout presented earlier in this paper addresses the shallow draw issue. Even more trials are planned and will be executed during a couple of years. The resources needed in terms of personnel and material/equipment using a holistic approach are high. A more customized approach has therefore been adopted for the future trials, Figure 9. Semi-horizontal holes are drilled into the pillar at the level above. These holes, used for installing markers, are only about $4 \mathrm{~m}$ long to avoid possible problems with blastholes drilled from the level below.
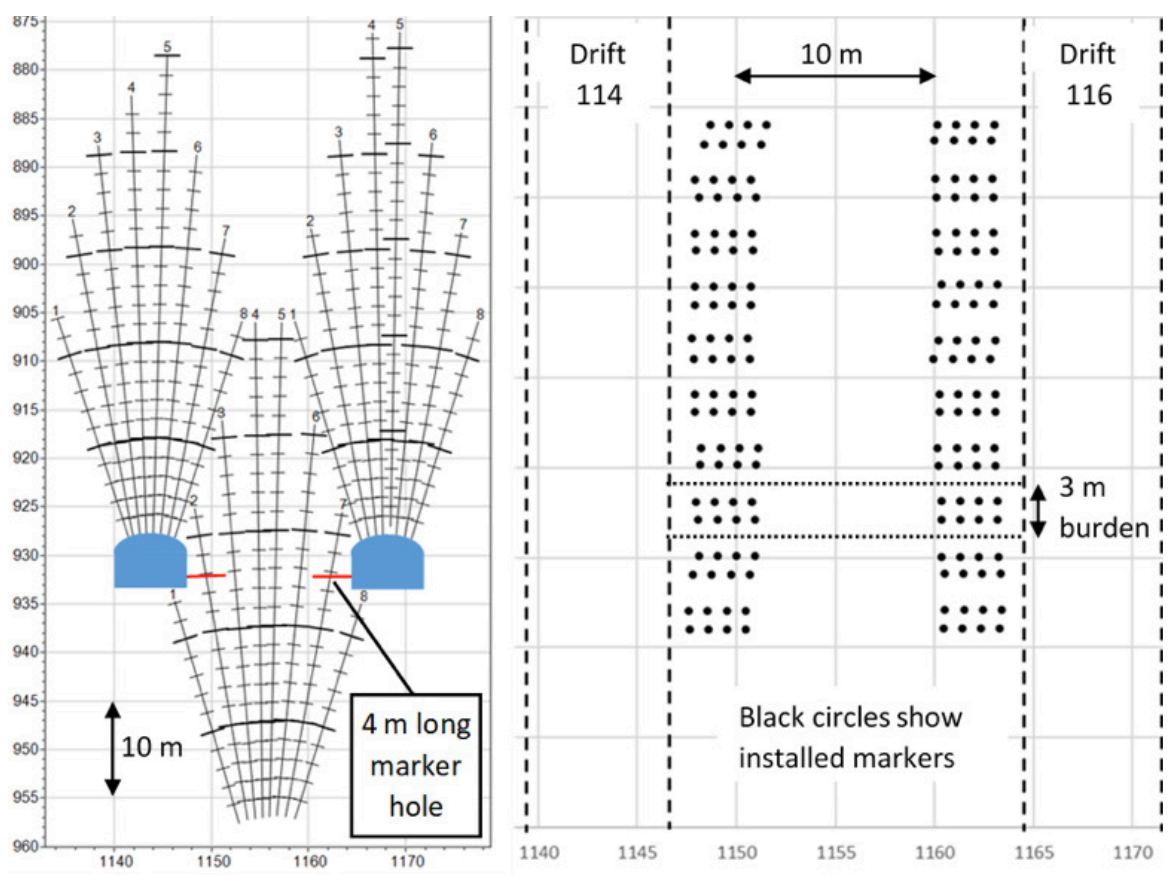

Figure 9 Customized marker trial layout. The front view (left) show short semi-horizontal holes drilled into the pillar at the level above. The top view (right) shows an example of installed marker positions, there are $\mathbf{4}$ marker holes in each burden 
There is a possibility that no markers will be detected when a very narrow draw $(<8-9 \mathrm{~m})$ is present. This is mitigated by increasing the number of rings in each trial. About 250-300 markers were installed in special marker rings drilled in each burden in marker trial 1-2. This enabled a very detailed view on the development of the draw during extraction. In the customized layout much less markers will be installed in each burden. The precise number might vary depending on the preferred distance between markers in each borehole but about 16-30 markers appears to be a reasonable choice. All markers are also located at a specific height in the ring, i.e. the level above. There are drawbacks with the customized layout in terms of resolution. It is however believed that it will give valuable information on the width of the draw and indicate possible presence of shallow draw.

\subsection{Specific trials}

Customized marker trials will be carried out during a couple of years, with the following being tested:

- Increased burden (from 3 to $3.5 \mathrm{~m}$ ) but otherwise maintained ring layout, coarser fragmentation is expected. This test will be carried out in the same mine area as marker trial 1 where a comparatively narrow draw was obtained. Possible reason is finer fragmentation.

- Increased ring inclination (from 80 to $85^{\circ}$ )

- Increased sublevel height (from 29 to 40 and $50 \mathrm{~m}$ )

- Standard rings located in three different orebodies in Malmberget mine

Besides monitoring gravity flow, additional instrumentation will be used when necessary.

The fragmentation varies in the Kiruna mine, fine fragmentation is expected in the northern part of the orebody and coarser in the southern. Based upon the shown influence of fragmentation on draw zone width, the burden is adjusted to $3.5 \mathrm{~m}$ in a test site at the northern part.

Shallow draw appears to be common especially in the northern part of the orebody. Besides the stepped layout an increased ring inclination is expected to increase the depth of the draw.

LKAB has recently initiated an industrial development project named "SUM", Sustainable Underground Mining (LKAB 2020) with the aim of setting a new world standard for sustainable mining at great depths. Together with partners, a dedicated test mine is built where new technology will be developed and tested in real mining environments. Part of that project are tests on extreme sublevel heights (Quinteiro 2020).

Recent marker trials have so far only been carried out in the Kiruna mine. LKAB also operates a SLC mine in Malmberget located about $100 \mathrm{~km}$ south of Kiruna. The annual production is about $16 \mathrm{Mt}$ crude ore or about $60 \%$ of Kiruna. These trials focus on the current situation, the gravity flow for standard rings in three main orebodies with different ring design will be monitored.

\section{Conclusions}

The combined results of the last decade has led to an increased and sufficiently accurate understanding of the functionality of present-day SLC. Even though not in detail described herein, a variety of possibilities for improvement were identified. In the short-term, a project named "SLC 1365" will focus on the optimization of working methods and techniques. It includes many incremental improvements when mining down to the main level at 1365 m, which still adds up to substantial change over time. Even if the research is based on the conditions in the Kiruna mine for the time being, most of the results are considered applicable to similar operations. The results obtained should also be used to calibrate numerical models.

In the long term, the present SLC design possibly may require a major review. Production on recent main levels in both LKAB underground mines will diminish after 2030. It is therefore indeed high time to design the future mining and production system. Crucial questions are related to the functionality of the 
SLC method and especially mastering of rock mechanical problems at large depth. Future infrastructure investments and the estimated higher production costs require an even more efficient production. It remains to be answered if this is achievable by upscaling again the SLC layout or if a new mining method needs to be developed. To address these questions, LKAB has recently started a framework program referred to as "Mine 5.0".

\section{Acknowledgements}

We are grateful to LKAB for the support when conducting research work during a long period of time and for approval to publish this paper. The authors also acknowledge colleagues and other personnel at LKAB Kiruna for their support when planning and executing the field test. Without their help this would not be achievable.

\section{References}

Forslund, M 2018, 'Framtida borrsystem - styrd skarvlös borrning under jord', Proc. Bergdagarna 2018, Swedish Rock Engineering Association, Stockholm, pp. 271-275, in Swedish.

Hustrulid, W \& Kvapil, R, 2008, 'Sublevel caving - past and future', in H Schunnesson, E Nordlund (eds), Proceedings of MassMin 2008, University of Technology, Lulea, Sweden, pp. 107-132.

Johansson, D 2011, 'Effects of confinement and initiation delay on fragmentation and waste rock compaction; Results from small scale tests', PhD thesis, Luleå University of Technology, Luleå.

Kullman, G \& Hermansson, L 1971, Prov standard - halvsilo - helsilometoden, final report T-798-71, LKAB, Kiruna. In Swedish.

Kvapil, R 1998, 'The mechanics and design of sublevel caving systems', in RE Gertsch \& RL Bullock (eds.), Techniques in underground mining - Selections from underground mining methods handbook, Society for Mining, Metallurgy and Exploration, Littleton, pp. 621-653.

Larsson, L 1998, Projekt Skivras 2000, final report 98-765, LKAB, Kiruna, in Swedish.

LKAB 2020, Information on SUM project. Available from: https://sustainableundergroundmining.com/

Nordqvist, A \& Wimmer, M 2016, 'Holistic approach to study gravity flow at the Kiruna sublevel caving mine', in C Carr \& G Chitombo (eds), Proceedings of MassMin 2016, Melbourne, pp. 401-414.

Nordqvist, A \& Wimmer, M 2014, 'Large-scale field test of gravity flow at the Kiruna mine', Proc. Aachen International Mining Symposia (AIMS), Druckservice Zillekens, Stolberg, pp. 621-636.

Nordqvist, A 2013, 'Mitigating nitrogen losses at the Kiruna in Sweden', Proc. 7th World Conference on Explosives and Blasting, Alliance Press, Moscow, pp. 86-90 (part II).

Olsson, M, Nyberg, U \& Fjellborg, S 2009, Kontrollerad sönderbrytning vid skivrassprängning - inledande försök, Swebrec Report 2009:2, Luleå University of Technology, Luleå, in Swedish.

Petropoulos, N 2020, 'Experiences from confined blasting tests at the sublevel caving mine in Kiruna', Proceedings of MassMin 2020, Santiago, Chile.

Petropoulos, N 2017, 'Improved understanding of sublevel blasting; Determination of the extent of the compacted zone, its properties and the effects on caving', PhD thesis, Luleå University of Technology, Luleå.'

Quinteiro, C 2020, 'Increasing sublevel height from 30 m to 50 m at LKAB', Proceedings of MassMin 2020, Santiago, Chile.

Quinteiro, C, Larsson, L \& Hustrulid, WA 2001, 'Theory and practice of very large scale sublevel caving', in WA Hustrulid \& RL Bullock (eds.), Underground mining methods - engineering fundamentals and international case studies, Society for Mining and Metallurgy, Littleton, pp. 381-384.

Rustan, A 2012, 'The dynamics and fragmentation of blasted ore slices in scaled sublevel caving and slab models followed by accuracy analysis of the "volume weight method" used for determination of ore content at loading', Proc. 10th International Symposium on Rock Fragmentation by Blasting, CRC Press, London, pp. 357-371. 
Rustan, A 2000, 'Gravity flow of broken rock - what is known and unknown', in G Chitombo (ed.), Proceedings of MassMin 2000, Australian Institute of Mining and Metallurgy, Melbourne, Australia, pp. 557-567.

Rustan, A 1993, 'Minimum distance between charged boreholes for safe detonation', Proc. 4th International Symposium on Rock Fragmentation by Blasting, Balkema, Rotterdam, pp. 127-135.

Stauder, S 2018, 'Behaviour of a novel algorithm for fragmentation analysis based on 3D images from photogrammetry', MSc thesis, Graz University of Technology, Graz.

Whiteman, DS 2010, 'The Smart Marker system - a new tool for measuring underground ore body flow in block and sublevel mines', Proc. 2nd International Symposium on block and sublevel caving, Australian Centre for Geomechanics, University of Western Australia, Perth, pp. 603-622.

Wimmer, M, Nordqvist A 2018, 'Present-day sublevel caving functionality uncovered - what's next?', Proc. 12th International Symposium on Rock Fragmentation by Blasting, Luleå University of Technology, Luleå, pp 469-480.

Wimmer, M, Nordqvist, N, Righetti E, Petropoulos N \& Thurley MJ 2015, 'Analysis of rock fragmentation and its effect on gravity flow at the Kiruna sublevel caving mine, Proc. 11th International Symposium on Rock Fragmentation by Blasting, Australasian Institute of Mining and Metallurgy, Carlton, pp. 775-791.

Wimmer, M, Nordqvist, A \& Billger, D 2014, 'Methodology for up-hole drilling accuracy measurements at Kiruna SLC mine', Proc. 3rd International Symposium on Block and Sublevel Caving, Universidad de Chile, Santiago, pp. 625-637.

Wimmer, M 2012, 'Towards understanding breakage and flow in sublevel caving (SLC); Development of new measurement techniques and results from dull-scale tests', PhD thesis, Luleå University of Technology, Luleå.

Wimmer, M, Nordqvist, A, Ouchterlony, F, Selldén, H \& Lenz, G 2012a, '3D mapping of sublevel caving (SLC) blast rings and ore flow disturbances in the LKAB Kiruna mine', Proceedings of MassMin 2012, Sudbury, Ontario, Canada, on CD only.

Wimmer, M, Nordqvist, A, Ouchterlony, F, Nyberg, U \& Furtney, J 2012b, 'Burden movement in confined drift wall blasting tests studies at the LKAB Kiruna SLC mine', Proc. 10th International Symposium on Rock Fragmentation by Blasting, CRC Press, London, pp. 373-383.

Wimmer, M 2010, Gravity flow of broken rock in sublevel caving - State-of-the-art, Swebrec Report 2010:P1, Luleå University of Technology, Luleå.

Zhang, G 2004, 'Behavior of caved ore mass in sublevel caving and its effect on ore dilution Proceedings of MassMin 2004, Santiago, Chile, pp. 238-242. 